\begin{tabular}{|c|c|c|}
\hline \multirow[t]{2}{*}{7} & $\begin{array}{l}\text { International Journal of Current Research in } \\
\text { Biosciences and Plant Biology }\end{array}$ & \\
\hline & Volume $4 \bullet$ Number 8 (August-2017) • ISSN: 2349-8080 (Online) & \\
\hline $\begin{array}{l}\text { EXCELLENT } \\
\text { PUBLISHERS } \\
\end{array}$ & Journal homepage: www.ijcrbp.com & wwwijecrip ocom \\
\hline
\end{tabular}

\title{
Antifungal Activity and Quantitative Phytochemical Analysis of Phyllodium pulchellum L. Desv.- An Important Medicinal Plant
}

\author{
Gopal Velmurugan* and Subramaniam Parvathi Anand
}

PG and Research Department of Botany, National College (Autonomous), Tiruchirappalli - 620 001, Tamil Nadu, India

*Corresponding author.

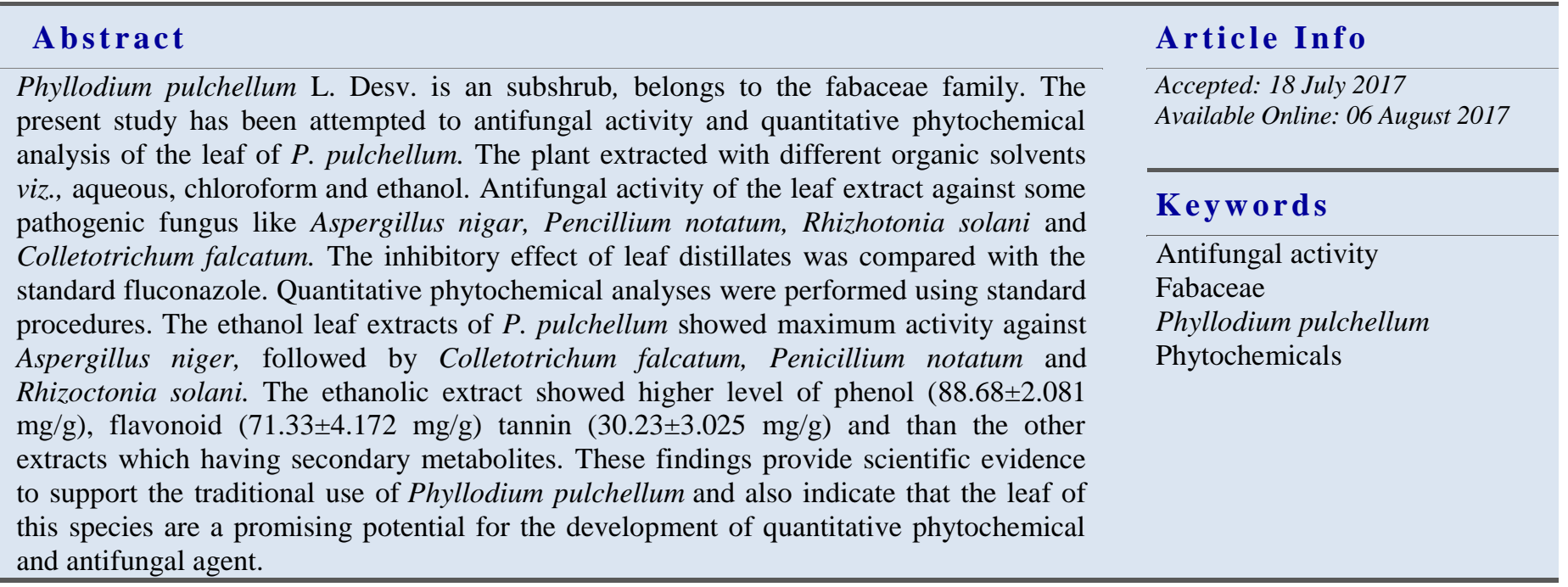

\section{Introduction}

Medicinal herb as a potential source of therapeutic aid has a significant role in health system all over the world for both humans and animals not only in the diseased condition but also as a potential material for maintaining proper health (Pathak and Das, 2013). Plants are a rich source of diverse type of medicines in different countries and produce a diverse array of bioactive molecules, the source of potential and powerful drugs (Vashist and Jindal, 2012). Thus, natural products with pharmacological or biological activities still play a very important role in medicine (Bhore et al., 2012). Plant extract has a potential application as natural medicine and to treat diseases as well as the microbiological safety of the human health (Subashkumar et al., 2013). Medicinal plants and their parts represent a rich source of antibacterial agents. Plants are used medicinally in different countries and are a source of many potent and powerful drugs. Different extracts from traditional medicinal plants have been tested. Many reports have show the effectiveness of traditional herbs against microorganisms, as a result, plants are one of the bedrocks for modern medicine to attain new principles (Dey et al., 2010). They have been widely used as traditional treatments for numerous human diseases. In 
less developed countries low income people such as farmers, people of small isolate villages and native communities use herbal medicine for the treatment of common infections. Phyllodium pulchellum is commonly known as Vellalothi which belongs to the family Fabaceae. $P$. pulchellum is an important medicinal plant and its leaf has been used in various ailments and as health tonic. Previously, no work has been carried out on the antifungal and quantitative phytochemical of leaf extracts of $P$. pulchellum, the present study dealing with the evaluation of phytochemicals and antimicrobial activities of leaf of $P$. pulchellum was undertaken.

\section{Materials and methods}

\section{Plant material}

Dried material of leaf parts was ground into fine powder in an electric blender and it was kept in airtight bottles at room temperature for further use.

\section{Preparation of crude extraction}

\section{Solvent of extraction}

For solvent extraction, $10 \mathrm{~g}$ of air-dried powder was taken in $100 \mathrm{ml}$ of organic solvent (ethanol and chloroform) in a conical flask, plugged with cotton wool and then kept on a rotary shaker at 190-220 rpm for 24 hrs. After $24 \mathrm{hrs}$ the supernatant was collected and the solvent was evaporated to make the final volume onefourth of the original volume (Parekh et al., 2005) and stored at $4^{\circ} \mathrm{C}$ in airtight bottles.

For aqueous extraction, $10 \mathrm{~g}$ of air-dried powder was added to distilled water and boiled on slow heat for 2 hrs. It was then filtered through 8 layers of muslin cloth and centrifuged at 5000rpm for $10 \mathrm{~min}$. The supernatant was collected. This procedure was repeated twice. After $6 \mathrm{hrs}$, the supernatant collected at an interval of every $2 \mathrm{hrs}$, was pooled together and concentrated to make the final volume one-fourth of the original volume. It was then autoclaved at $121^{\circ} \mathrm{C}$ temperature and at $15 \mathrm{lbs}$ pressure and stored at $4^{\circ} \mathrm{C}$.

\section{Fungal isolates and their maintenance}

The fungi employed in the study were Penicillium notatum (MTCC 4634), Aspergillus niger (MTCC 4325), Rhizoctonia solani (MTCC 4634) and
Colletotrichum falcatum (lab strain). The isolates were procured from the MTCC, Chandigarh. The isolates were maintained on Potato Dextrose Agar slants by sub culturing at monthly intervals.

\section{Screening of fungi for sensitivity towards plant extracts}

PDA plates with crude plant extracts were used for testing the antifungal activity of plant extracts (Sharma et al., 2012). The discs were prepared by incorporating plant extracts in various concentrations.

\section{Experimental procedure}

The PDA plates were inoculated with fungal cultures and plant extract loaded sterile disc was impregnated on the surface of the medium and the plates were incubated in a humid chamber at room temperature. The activity of the extract was assessed by measuring the zone of inhibition and recorded.

\section{Determination of total phenolic, total flavonoid and total tannin contents}

\section{Total phenolic content (TPC)}

The amount of total phenolics in extracts was determined with the Folin-Ciocalteu reagents method described by Demiray et al. (2009). Gallic acid was used as a standard and the total phenolics were expressed as $\mathrm{mg} / \mathrm{g}$ gallic acid equivalents (GAE). Concentration of 20 to $100 \mu \mathrm{g} / \mathrm{ml}$ of working standard solution was taken into a series of test tubes. The leaf extract were also prepared in various solvents about $0.125 \mathrm{ml}$ of each sample were introduced into test tubes. To all the test tubes, including the blank, add distilled water to make up to $3.5 \mathrm{ml}$ and add $0.125 \mathrm{ml}$ of Folin's phenol reagent. Incubate the test tubes at room temperature for 6 minutes and add $1.25 \mathrm{ml}$ of $7 \%$ sodium carbonate in all the test tubes. The tubes were covered with parafilm and allowed to stand for 90 minutes at room temperature before the absorbance was read at $760 \mathrm{~nm}$ spectrometrically.

All determinations were performed in triplicate. The Folin-Ciocalteu reagent being sensitive to reducing compounds including polyphenols is producing a blue colour upon reaction which is measured spectrophotometrically.

GAE was calculated using the following equation: 


$$
\mathrm{C}=\frac{(\mathrm{cxV})}{\mathrm{m}}
$$

Where, $\mathrm{C}=$ total content of flavonoid compounds $(\mathrm{mg} / \mathrm{g})$ plant extract, in quercetin equivalent, $\mathrm{c}=$ the concentration of quercetin established from the calibration curve $(\mathrm{mg} / \mathrm{ml}), \mathrm{V}=$ the volume of extract $(\mathrm{ml})$, and $\mathrm{m}=$ the weight of crude plant extract $(\mathrm{g})$.

\section{Total flavonoid content (TFC)}

The total flavonoids content of plant extract was estimated by Aluminium chloride method. (Wang and Jiao, 2000). Pipette out 0.5, 1.0, 1.5, 2.0 and $2.5 \mathrm{ml}$ (Concentration varying from 50 to $250 \mu \mathrm{g}$ ) of the standard solution into a series of test tubes. Add 0.1 $\mathrm{ml}$ of the plant sample into test tubes. To all test tubes, including the blank, add distilled water to make up to $2.5 \mathrm{ml}$. After that to all tubes add $75 \mu \mathrm{l}$ of $5 \%$ $\mathrm{NaNO}_{2}$ and incubate at room temperature for 5 minutes. Add $150 \mu \mathrm{l}$ of $10 \% \mathrm{AlCl}_{3}$ and incubate at room temperature for 6 minutes. Then add $0.5 \mathrm{ml}$ of 1 $\mathrm{M} \mathrm{NaOH}$, mix well and the pink coloured substance formed is spectrophotometrically measured at $510 \mathrm{~nm}$. All determinations were performed in triplicates. Calculate the unknown sample concentration from the standard curve of the graph. The total content of flavonoid compounds was calculated by the following equation.

$$
\mathrm{C}=\frac{(\mathrm{cxV})}{\mathrm{m}}
$$

Where, $\mathrm{C}=$ Total content of flavonoid compounds $(\mathrm{mg} / \mathrm{g})$ plant extract, in quercetin equivalent, $\mathrm{c}=$ The concentration of quercetin established from the calibration curve $(\mathrm{mg} / \mathrm{ml}), \mathrm{V}=$ The volume of extract $(\mathrm{ml})$, and $\mathrm{m}=$ The weight of crude plant extract $(\mathrm{g})$.

\section{Total tannin content (TTC)}

The total tannin content of plant extract was estimated by modified Prussian blue method (Graham, 1992). Tannic acid was used as a standard and the total tannins were expressed as $\mathrm{mg} / \mathrm{g}$ tannic acid equivalents (TAE). Pipette out $0.1,0.2,0.3,0.4$ and $0.5 \mathrm{ml}$ (Concentration varying from 10 to $50 \mu \mathrm{g}$ ) of the working standard solution into a series of test tubes. Add $0.1 \mathrm{ml}$ of sample and to all the test tube, including the blank, add distilled water to make up to $7 \mathrm{ml}$. To all the test tubes, add $1 \mathrm{ml}$ of potassium ferricyanide and 1 $\mathrm{ml}$ of $\mathrm{FeCl} 3$ mix well. Measure the absorbance spectrophotometrically at $700 \mathrm{~nm}$. From the standard curve of the graph, calculate the unknown sample concentration. All determinations were performed in triplicate. The total content of tannin compounds was calculated by the following equation:

$$
\mathrm{C}=\frac{(\mathrm{cxV})}{\mathrm{m}}
$$

Where, $\mathrm{C}=$ total content of tannin compounds $(\mathrm{mg} / \mathrm{g})$ plant extract, in tannic acid equivalent, $\mathrm{c}=$ the concentration of tannic acid established from the calibration curve $(\mathrm{mg} / \mathrm{ml}), \mathrm{V}=$ the volume of extract (ml) and $\mathrm{m}=$ The weight of crude plant extract $(\mathrm{g})$.

\section{Results}

\section{Antifungal activity}

The results of antifungal property of $P$. pulchellum were extracted with different organic solvents viz., aqueous, chloroform and ethanol. The antifungal activity of the leaf extract against some pathogenic fungus like Aspergillus niger, Penicillium notatum, Rhizoctonia solani and Colletotrichum falcatum are given in Table 1 and Fig. 1. The antifungal activity was tested by disc diffusion method (Taylor et al., 1995).

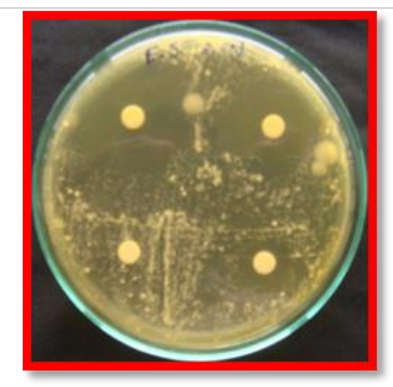

Aspergillus nigar

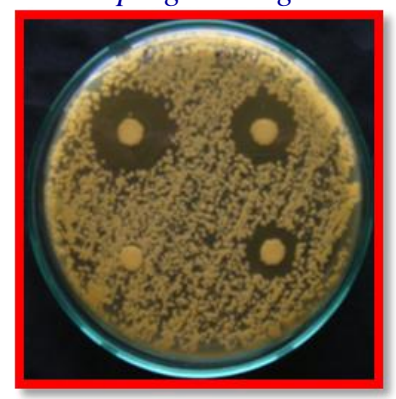

Rhizhotonia solani

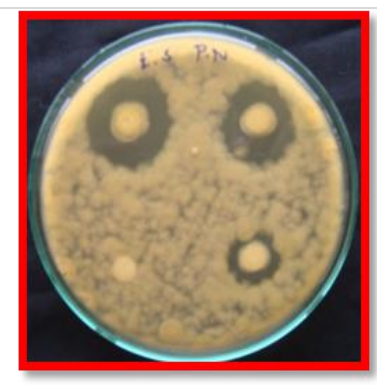

Pencillium notatum

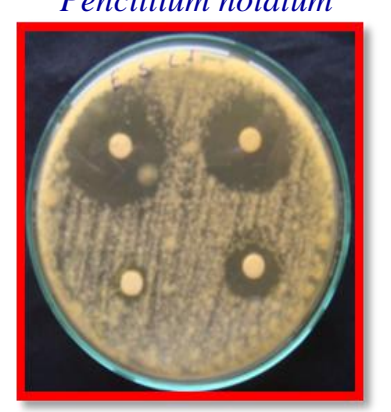

Colletotrichum falcatum
Fig. 1: Antifungal activity of $P$. pulchellum ethanol leaf extract. 
The ethanol extracts of P.pulchellum showed maximum activity against Aspergillus niger, followed by Colletotrichum falcatum, Penicillium notatum and Rhizoctonia solani. The chloroform extract of this plant showed maximum activity against Colletotrichum falcatum, followed by Aspergillus niger, Penicillium notatum and Rhizoctonia solani. The antifungal activity of ethanol extracts showed more effective followed by chloroform extract against all the fungal strains. The water extract doesn't show comparative effectiveness on the pathogenic fungi with ethanol and chloroform extracts. As compared with fluconazole, the positive control ethanolic extract of $P$. pulchellum showed high activity against all the pathogenic fungi. It was evident that the inhibition of growth of fungus was more prominent with ethanol extract than chloroform extract.

Table 1. Antifungal activity of various extracts of P.pulchellum.

\begin{tabular}{|c|c|c|c|c|c|}
\hline \multirow[b]{2}{*}{ Test microorganisms } & \multirow[b]{2}{*}{$\begin{array}{l}\text { Concentration } \\
\text { (mg) }\end{array}$} & \multicolumn{3}{|c|}{ Zone of Inhibition (mm) } & \multirow[b]{2}{*}{$\begin{array}{l}\text { Fluconazole } \\
10 \text { mcg / disc }\end{array}$} \\
\hline & & $\begin{array}{l}\text { Aqueous } \\
\text { extract }\end{array}$ & $\begin{array}{l}\text { Chloroform } \\
\text { extract }\end{array}$ & $\begin{array}{l}\text { Ethanol } \\
\text { extract }\end{array}$ & \\
\hline \multirow{4}{*}{ Aspergillus nigar } & 25 & - & 1.0 & 0.8 & \multirow[t]{4}{*}{2.6} \\
\hline & 50 & - & 1.8 & 1.2 & \\
\hline & 75 & - & 2.4 & 2.4 & \\
\hline & 100 & - & 2.8 & 3.6 & \\
\hline \multirow[t]{4}{*}{ Pencillium notatum } & 25 & - & - & - & \multirow[t]{4}{*}{2.4} \\
\hline & 50 & - & 1.6 & 1.2 & \\
\hline & 75 & - & 2.2 & 1.8 & \\
\hline & 100 & - & 2.4 & 2.5 & \\
\hline \multirow[t]{4}{*}{ Rhizhotonia solani } & 25 & - & 0.8 & - & \multirow[t]{4}{*}{2.0} \\
\hline & 50 & - & 1.2 & 1.4 & \\
\hline & 75 & - & 1.8 & 2.0 & \\
\hline & 100 & - & 2.4 & 2.5 & \\
\hline \multirow{4}{*}{ Colletotrichum falcatum } & 25 & - & 1.0 & 0.8 & \multirow[t]{4}{*}{2.6} \\
\hline & 50 & - & 1.6 & 1.0 & \\
\hline & 75 & - & 2.4 & 2.2 & \\
\hline & 100 & - & 3.0 & 3.0 & \\
\hline
\end{tabular}

\section{Quantitative analysis}

Quantitative phytochemical analysis was studied for total flavonoids, phenol and tannin contents, which were responsible for the major pharmacological activity of the plants. For the quantification of leaf extracts having strong presence of phenols, flavonoids and tannin contents were determined. Knowledge of the chemical constituents of plants is desirable because such information will be of value for synthesis of complex chemical substances. Hence, to characterize the formulation of total flavonoids, phenol and tannins contents were estimated and shown in (Table 2).

Table 2. Total Flavonoids, Phenolic and Tannin contents of P. pulchellum of leaf extracts.

\begin{tabular}{llll}
\hline $\begin{array}{l}\text { Extracts } \\
\text { leaf }\end{array}$ & Total flavonoids content $(\mathbf{m g} / \mathbf{g})$ & Total phenolic content $(\mathbf{m g} / \mathbf{g})$ & Total tannin content $(\mathbf{m g} / \mathbf{g})$ \\
\hline Aqueous & $26.66 \pm 4.163$ & $80.12 \pm 3.055$ & $30.23 \pm 3.025$ \\
Ethanol & $\mathbf{7 1 . 3 3 \pm 4 . 1 7 2}$ & $\mathbf{8 8 . 6 8} \pm \mathbf{2 . 0 8 1}$ & $\mathbf{4 0 . 7 2 \pm 5 . 1 3 1}$ \\
Chloroform & $27.61 \pm 3.511$ & $35.36 \pm 1.814$ & $14.33 \pm 7.023$ \\
\hline
\end{tabular}

\section{Determination of total flavonoids content}

The total flavonoid content of the extract was expressed in quercetin equivalents. Total flavonoid content in various solvent extracts such as aqueous, ethanol and chloroform were found to be $26.66 \pm 4.163 \mathrm{mg} / \mathrm{g}, 71.33$ $\pm 4.172 \mathrm{mg} / \mathrm{g}$ and $27.61 \pm 3.511 \mathrm{mg} / \mathrm{g}$ quercetin equivalents/g dry weight. Ethanolic leaf extract of
Phyllodium pulchellum was found to contain the highest amount of flavonoid. It has been recognized that flavonoids show antioxidant activity and their effects on human nutrition and health are considerable.

\section{Determination of total phenolic content}

The content of total phenol in the extracts of Phyllodium 
pulchellum was determined by using the FolinCiocalteu assay and expressed as gallic acid equivalents (GAE). The total phenol content of the test fractions were calculated using the standard curve of gallic acid. In ethanol leaf extracts of higher amount of total phenol content was found to be $88.68 \pm 2.081 \mathrm{mg} / \mathrm{g}$. The descending orders of the total phenol content of extract in ethanol $>$ aqueous $>$ chloroform.

\section{Determination of total tannins content}

The total tannin contents of different leaf extracts of Phyllodium pulchellum were determined and found to be $30.23 \pm 3.025 \mathrm{mg} / \mathrm{g}, 40.72 \pm 5.131 \mathrm{mg} / \mathrm{g}$ and $14.33 \pm$ $7.023 \mathrm{mg} / \mathrm{g}$ with respect to various solvents, as follows aqueous, ethanol and chloroform. Total tannin content was calculated using the standard curve of tannic acid and was expressed as tannic acid equivalents (TAE) per gram of the plant extract. Ethanolic leaf extract of Phyllodium pulchellum was found to contain the maximum amount of tannin. Tannin contents of the extracts were found to decrease in the following order of Ethanol extract $>$ Aqueous extract $>$ Chloroform extract.

\section{Discussion}

The present study is the first report on the antifungal activity of various extracts of Phyllodium pulchellum. An ethanol extract of the leaf shows high activity against the fungal strains than other extracts. The study evidences that plant species are having antifungal activity of their own for survival in different environmental conditions. The finding in disc diffusion assay of leaf extracts of Phyllodium pulchellum correlate with the results of earlier works like Desmodium gangeticium (Vijayalakshmi et al., 2011), Desmodium heterocarpon (Al Hasan et al., 2011), Desmodium elegans (Khan et al., 2013), Aloe vera (Arunkumar and Muthuselvam, 2009), Mimosa pudica (Gandhiraja et al., 2009).

The quantitative estimation of primary metabolites reveals various chemical constituents present in the plant. Quantization of the phytocompounds such as phenol, flavonoids and tannins from various solvent extracts of Phyllodium pulchellum was studied in this work. Highest concentrations of the bioactive principles were detected in ethanolic extracts of the plants, except in the case of tannins where chloroform extract produced the bioactive compounds. The ethanolic extract showed higher level of phenols $(88.68 \mathrm{mg} / \mathrm{g}$ of dried weight) than the other extracts which having secondary metabolites. The higher amount of phenol is important in regulation of plant growth, development and disease resistance. Triterpenoid saponins, tetrahydroiso-quinolones, phenylethylamines and indole-3-alkyl amines have been isolated from the leaves of Desmodium adscendens (Addy, 1989). Similar results were reported in Indigofera tinctoria (Singh et al., 2015).

\section{Conclusion}

In the present study conclude that the Phyllodium pulchelllum leaf have the potential to act as a source of useful drugs because of presence of various phytochemical constituents such as alkaloids, flavonoids and phenol. Thus, these plants have great potential as antimicrobial agents and can be used in the treatment of infectious diseases caused by resistant microorganisms. The finding of this study suggests that this plant leaf could be a potential source of natural phytochemical and antifungal activity that could have great importance as therapeutic agents. Further investigation on the isolation and characterization of the antioxidant constituents is however required.

\section{Conflict of interest statement}

Authors declare that they have no conflict of interest.

\section{References}

Addy, M.E., 1989. Several chromatographically distinct components from Desmodium adscendens inhibit smooth muscle contractions. Int. J. Crude Drug Res. 27, 81-91.

Al Hasan, A., Hasan, C.M., Azam, A.Z., 2011. Antimicrobial, Cytotoxic and Antioxidant Activities of Desmodium heterocarpon. Bangladesh Pharmaceutical Journal. 14(1), 49-52.

Arunkumar, S., Muthuselvam, M., 2009. Analysis of phytochemical constituents and antimicrobial activities of Aloe vera L. against clinical pathogens. World Journal of Agricultural Sciences. 5(5), 572-576.

Bhore, N.V., Pishawikar, S.A., More, H.N., 2012. Phytochemical screening and antioxidant activity of flowers (inflorescence) of Saccharum officinarum linn. Int. J. Res. Pharm. Biomed. Sci. 3(2), 620-624.

Demiray, S., Pintado, M.E., Castro, P.M.L., 2009. Evaluation of phenolic profiles and antioxidant activities of Turkish medicinal plants: Tilia 
argentea, Crataegi folium leaves and Polygonum bistorta roots. World Academy of Science Engineering and Technology. 54, 312-317.

Dey, S.K., Banerjee, D., Chattapadhyay, S., Karmakar, K.B., 2010. Antimicrobial activities of some medicinal plants of West Bengal. International Journal of Pharma and Bio Sciences. 1(3), 1-10.

Gandhiraja, N., Sriram, S., Meenaa, V., Srilakshmi, J.K., Sasikumar, C., Rajeswari, R., 2009. Phytochemical screening and antimicrobial activity of the plant extracts of Mimosa pudica L. against selected microbes. Ethnobotanical leaflets. 13, 618-24.

Graham, H.D., 1992. Stabilization of the Prussian blue color in the determination of polyphenols. Journal of agricultural and food chemistry. 40(5), 801-805.

Khan, A., Usman, R., Rauf, A., Wang, M.L., Muhammad, N., Aman, A., Tahir, T.H.M. (2013). In vitro biological screening of the stem of Desmodium elegans. Asian Pacific journal of tropical biomedicine. 3(9), 711-715.

Parekh, J., Karathia, N., Chanda, S., 2005. Evaluation of antibacterial activity and phytochemical analysis of Bauhinia variegata L. bark. African Journal of Biomedical Research. 9(1), 53-56.

Pathak, K., and Das, R.J., 2013. Herbal medicine-a rational approach in health care system. International Journal of Herbal Medicine, 1(3), 8689.

Sharma, R.K., Vyas, K., Manda, H., 2012. Evaluation of
Antifungal Effect on Ethanolic Extract of Lepidium Sativum L. Seed. International Journal of Phytopharmacology. 1(3), 117-120.

Singh, R., Sharma, S., Sharma, V., 2015. Comparative and quantitative analysis of antioxidant and scavenging potential of Indigofera tinctoria Linn. extracts. Journal of integrative medicine, 13(4), 269278.

Subashkumar, R., Sureshkumar, M., Babu, S., Thayumanavan T., 2013. Antibacterial effect of crude aqueous extract of Piper beetle L. against pathogenic bacteria. Int. J. Res. Pharm. Biomed. Sci. 4(1), 42-46.

Taylor, R. S., Manandhar, N.P., Towers, G.H.N., 1995. Screening of selected medicinal plants of Nepal for antimicrobial activities. Journal of Ethnopharmacology, 46(3), 153-159.

Vashist, H., Jindal, A., 2012. Antimicrobial activities of medicinal plants-Review. Int. J. Res. Pharm. Biomed. Sci. 3(1), 222-230.

Vijayalakshmi, G., Deepti, K., Lakshmi, P.A.K., 2011. Phytochemical evaluation and antimicrobial activity of crude extracts of Desmodium gangeticium DC. Journal of Pharmacy Research. 4(7), 2335-2337.

Wang, S.Y., Jiao, H., 2000. Scavenging capacity of berry crops on superoxide radicals, hydrogen peroxide, hydroxyl radicals, and singlet oxygen. Journal of Agricultural and Food Chemistry. 48(11), 5677-5684.

\section{How to cite this article:}

Velmurugan, G., Parvathi Anand, S., 2017. Antifungal activity and quantitative phytochemical analysis of Phyllodium pulchellum L. Desv.- An important medicinal plant. Int. J. Curr. Res. Biosci. Plant Biol. 4(8), 67-72. doi: https://doi.org/10.20546/ijcrbp.2017.408.009 